\title{
Biochemical, molecular and clinical aspects of coagulation factor VII and its role in hemostasis and thrombosis
}

\author{
Francesco Bernardi ${ }^{1}$ and Guglielmo Mariani ${ }^{2}$ \\ ${ }^{1}$ Department of Life Science and Biotechnology, University of Ferrara, Ferrara, Italy and \\ ${ }^{2}$ Department of Science and Technology, University of Westminster, London, UK
}

\section{ABSTRACT}

\begin{abstract}
A ctivated factor VII (FVIIa), the first protease of clotting, expresses its physiological procoagulant potential only after complexing with tissue factor (TF) exposed to blood. Deep knowledge of the FVIIa-TF complex and F7 gene helps to understand the Janus-faced clinical findings associated to low or elevated FVII activity (FVIIc). Congenital FVII deficiency, the most frequent among the recessively inherited bleeding disorders, is caused by heterogeneous mutations in the F7 gene. Complete FVII deficiency causes perinatal lethality. A wide range of bleeding symptoms, from life-threatening intracranial hemorrhage to mild mucosal bleeding, is observed in patients with apparently modest differences in FVIIc levels. Though clinically relevant FVIIc threshold levels are still uncertain, effective management, including prophylaxis, has been devised, substantially improving the quality of life of patients. The exposure of TF in diseased arteries fostered investigation on the role of FVII in cardiovascular disease. FVIIc levels were found to be predictors of cardiovascular death and to be markedly associated to F7 gene variation. These genotype-phenotype relationships are among the most extensively investigated in humans. Genome-wide analyses extended association to numerous loci that, together with $F 7$, explain $>50 \%$ of FVII level plasma variance. However, the ability of $F 7$ variation to predict thrombosis was not consistently evidenced in the numerous population studies. Main aims of this review are to highlight i) the biological and clinical information that distinguishes FVII deficiency from the other clotting disorders and ii) the impact exerted by genetically predicted FVII level variation on bleeding as well as on the thrombotic states.
\end{abstract}

\section{Introduction}

Blood coagulation is initiated by the formation of a complex between tissue factor (TF), a single-pass transmembrane glycoprotein, and activated factor VII (FVIIa), a serine protease highly dependent for its procoagulant activity on TF.1.4 The absence of either of these components is incompatible with life. ${ }^{5}$ However, small amounts of these proteins, interacting in the FVIIa-TF complex, are sufficient to initiate a number of reactions ${ }^{6}$ on membrane surfaces. ${ }^{4}$ The FVIIa-TF complex might also possess non-hemostatic, signaling properties.

Detailed knowledge of the physiological and biochemical properties of FVIIa has enabled its pharmacological application as recombinant FVIIa (rFVIIa), a landmark in the management of bleeding disorders. ${ }^{8}$ Genetic $^{9}$ and clinical studies have defined the heterogeneous molecular basis ${ }^{10-12}$ of FVII deficiency ${ }^{13}$ and could lay the foundations for gene therapy.

Extensive plasma studies and genetic investigations ${ }^{14}$ have defined the importance of the $F 7$ gene variation in determining the large FVII variance in plasma concentration, ${ }^{15}$ with implications in predisposition to thrombosis ${ }^{16-18}$ in both individuals and the population as a whole.

A comprehensive review on FVII is complex because of the wealth of information available both in the field of hemostasis and thrombosis (Figure 1). The main aim of this review is to provide an integrated and balanced perspective of the bio-
Haematologica 2021

Volume 106(2):351-362

\section{Correspondence:}

FRANCESCO BERNARDI

ber@unife.it

Received: July 3, 2020.

Accepted: October 29, 2020.

Pre-published: January 7, 2021.

https://doi.org/10.3324/haematol.2020.248542

(C)2021 Ferrata Storti Foundation

Material published in Haematologica is covered by copyright. All rights are reserved to the Ferrata Storti Foundation. Use of published material is allowed under the following terms and conditions:

https://creativecommons.org/licenses/by-nc/4.0/legalcode. Copies of published material are allowed for personal or internal use. Sharing published material for non-commercial purposes is subject to the following conditions: https://creativecommons.org/licenses/by-nc/4.0/legalcode, sect. 3. Reproducing and sharing published material for commercial purposes is not allowed without permission in writing from the publisher. 
logical and clinical information currently available. That is, the relationship between the reduced levels of FVII/bleeding tendency and high levels of FVII/ risk of cardiovascular disease. We will particularly focus on distinctive features of the FVII protein and F7 gene (Table 1) as well as on open issues (Table 2).

\section{Genetics and biochemical aspects}

Expression of the F7 gene and FVII protein is shown in Figure 2. Key biochemical and genetic findings are summarized on a historical time line in Figure 1A, and some of the key unanswered questions are summarized in Table 2 . The F7 gene $(12.8 \mathrm{~KB})$ is located on chromosome 13q34, $2 \mathrm{~KB}$ apart from the homologous F10 gene, which suggests evolution by duplication. In addition to $F 10$, the F7 gene structure and coding sequence ${ }^{19}$ displays a noticeable homology also with F9 (factor IX, FIX) and PROC (protein C).

Mutations that disrupt promoter activity in severe FVII deficiency ${ }^{20,21}$ highlight the importance of the transcription factors SP1 and HNF4 $\alpha$, but do not sustain the androgen- dependent rescue observed for mutations in the F9 promoter in hemophilia B. The evolutionary history of the F7 promoter region, which contains frequent polymorphisms ${ }^{22,23}$ modulating FVII expression (see dedicated paragraph), may differ in human populations.

The F7 gene gives rise to three mRNA transcripts ${ }^{12}$ through FVII mRNA alternative splicing. Whereas two transcripts (NM_019616.4 and NM 000131.4) encode an identical mature and circulating FVII protein, the third (NM_001267554.1) lacks the amino terminal domains and is of unknown physiological significance.

\section{The FVII protein and FVIIa-TF complex}

A scheme of FVII activation, activity and inhibition is shown in Figure 3. Whereas the mature circulating FVII protein $(50 \mathrm{KDa})$ sequence $^{19}$ is composed of 406 residues, the mRNA (NM_019616.4) encodes 60 additional aminoacids, the pre-propeptide sequences which drive FVII biosynthesis/secretion and are removed by intracellular proteolysis (Figure 2). The first numbering (1-406 residues) is currently used in protein studies, and the second one (1-466 codons) in molecular genetics.

A

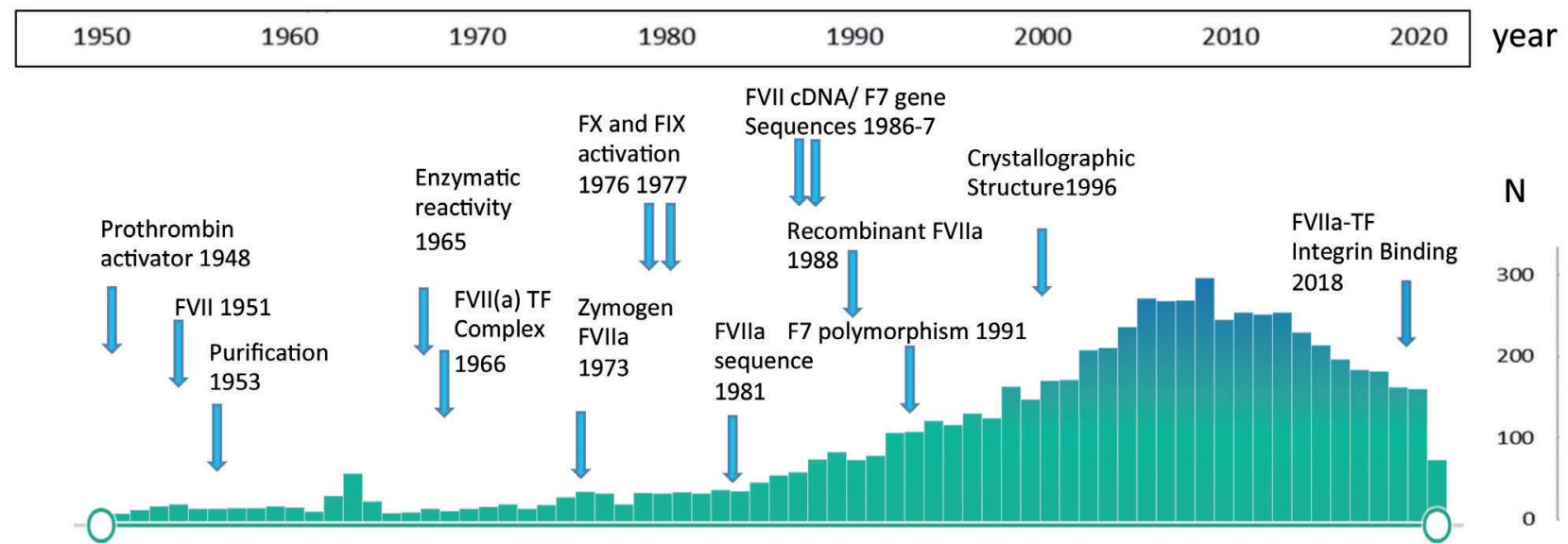

B

\begin{tabular}{|llllllll|}
\hline 1950 & 1960 & 1970 & 1980 & 1990 & 2000 & 2010 & 2020 \\
year
\end{tabular}

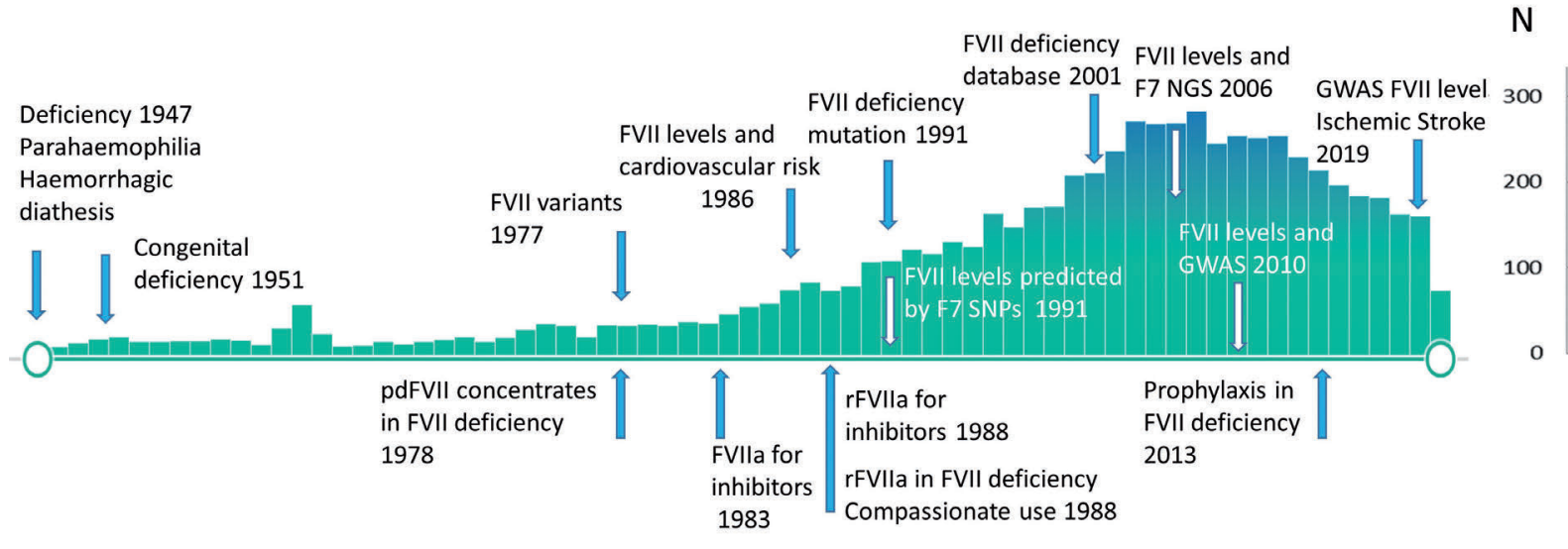

Figure 1. Publications over 70 years and some key achievements related to coagulation factor VII. (A) Coagulation factor VII (FVII) biochemistry and F7 genetics. (B) FVII deficiency, FVII level associated cardiovascular disease, FVII levels and F7 gene: N: number of publications reported in Pubmed. Only some of the discoveries are referenced in the text due to space constraints. A complete list is available on request. GWAS: Genome Wide Analysis Study; NGS: next-generation sequencing. 
FVII zymogen circulates in plasma at low concentration $(500 \mathrm{ng} / \mathrm{mL}, 5 \mathrm{nM})$ and the extracellular proteolytic cleavage $^{1}$ of a minute portion (about 1\%, $0.1 \mathrm{nM}$ ) of FVII giving rise to FVIIa, occurs between residues Arg152-Ile153, (Figure 2$)^{2}$ producing the light and heavy chains. The origin of FVIIa in plasma is still debated. Substantially decreased levels of plasma FVIIa in individuals with congenital FIX deficiency suggest that the generation of FVIIa is dependent on an activation product of FIX. Recently, it has been proposed that different forms of activated FIX (FIX $\alpha$ and FIX $\beta$ ) participate in a reciprocal activation mechanisms of FVII (a) and FIX(a) (white and red-curved arrows, Figure 3, left panel) that would not require a protein cofactor. ${ }^{24}$

The FVIIa heavy chain contains the domain characterized by the (chymotrypsin) serine protease family catalytic triad. The light chain contains the calcium binding, vitamin K-dependent domain (gamma-carboxyl-glutamic, GLA) and two epidermal growth factor-like domains, essential for the interaction with membranes and other proteins ${ }^{2}$ of the coagulation cascade.

Considerable variation in FVIIa plasma concentrations between individuals has been reported (Figure 4), ${ }^{25}$ exceeding one order of magnitude. Differently from other serine protease of the coagulation cascade, FVIIa displays a plasma half-life (2-3 hours) remarkably close to that of the FVII zymogen, which might be explained by the "zymogenlike" properties of FVIIa that have been weakened by mutagenesis, thus increasing its activity. ${ }^{26}$

FVIIa interacts with TF, a membrane receptor exposed following vascular lesion (extrinsic pathway). The FVIIaTF complex, ${ }^{1}$ essentially conserved in all jawed vertebrates, ${ }^{27}$ activates both FIX and factor X $(\mathrm{FX})^{28}$ (Figure
3) on the platelet surface in the presence of $\mathrm{Ca}^{2+}$, leading to the generation of thrombin and the subsequent deposition of fibrin.

The crystal structure of the complex between the activesite-inhibited FVIIa and the cleaved, soluble extracellular domain of TF (sTF) revealed the details of the contoured embrace of FVIIa and STF domains and the extensive intermolecular contacts. ${ }^{29}$ Neutron and X-ray scattering experiments ${ }^{30}$ suggested that FVIIa in solution has an elongated domain structure with significant flexibility, which allows rapid interaction with sTF over a large surface area to form the high-affinity complex (dissociation constant, KD 2-5 $\mathrm{nM}$ ).

The FVIIa-TF complex is highly dependent on specific lipids for physiological activity. ${ }^{2}$ Activated phospholipid membranes host both TF, an integral membrane protein, and FVIIa, which binds membranes through its GLA domain. Externalization of phosphatidylserine to the outer membrane leaflet and allosteric TF disulphide bond exchanges (decryption on membranes) ${ }^{4}$ make TF the FVIIaactivating cofactor. The FVIIa-TF complex formation shapes the FVIIa catalytic site by allosteric interactions and increases its activity up to $10^{6}$-fold. As a matter of fact, circulating FVIIa is the active portion of the total FVII mass only after high-affinity binding with TF. These FVIIa-TF complex-specific molecular events that provide FVIIa with its physiological activity are believed to represent the true initiation of the extrinsic pathway (Table 1).

The physiological negative control of the FVIIa-TF complex (Figure 3) occurs through the reversible inhibition by tissue factor pathway inhibitor (TFPI), ${ }^{31}$ mediated by the TFPI Kunitz domain 1 and with protein $S$ as cofactor. ${ }^{32}$ An

\section{Chomosome 13}

$12.8 \mathrm{~KB}$
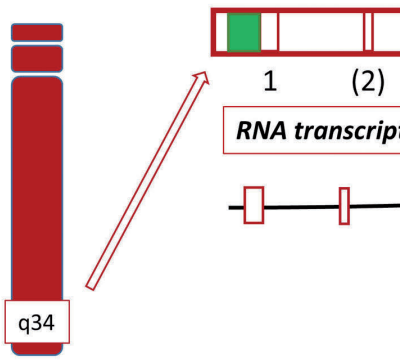

$\mid$

[

\section{$\|$}

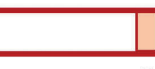

1

1

\begin{tabular}{ll|}
\hline & \\
\hline & 9
\end{tabular}
]

F7 gene

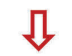

Nuclear RNA transcript $\sqrt{2}$
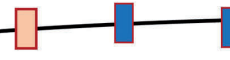

mRNA splicing and maturation

凤

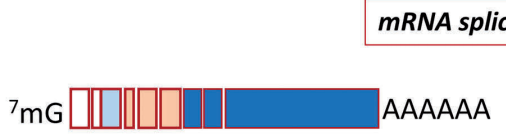

mRNA

Л

mRNA translation

Protein
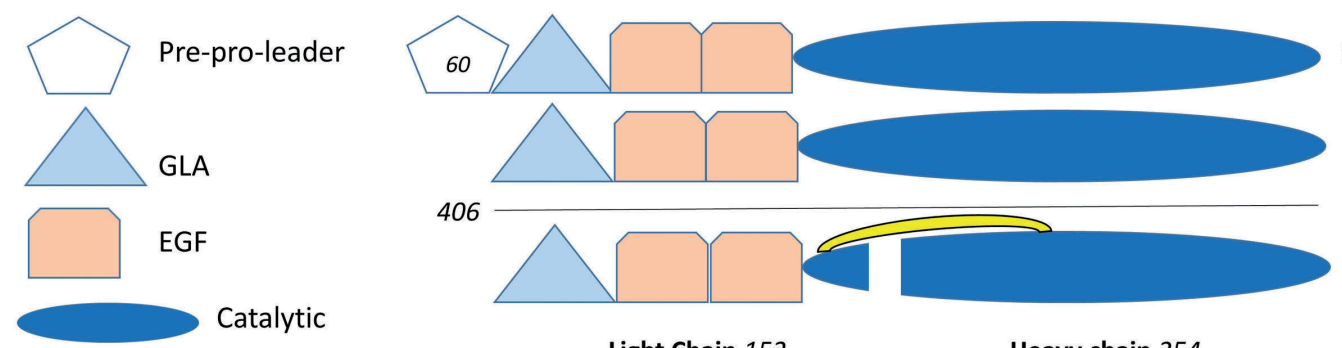

intracellular

zymogen

406
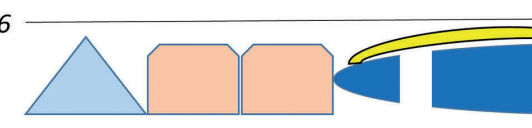

Light Chain 152

Heavy chain 254

Figure 2. Schematic diagram of the $F 7$ gene and factor VII protein expression. Upper part: Exons are numbered (1-9) and colored in accordance with the encoded protein domains (lower part). Exon 2 is in parenthesis because it is not included in the most abundant mature mRNA. FVII: factor VII; F7: factor VII gene; KB: kilobase. In addition to the complete nuclear transcript the most represented FVII mRNA is indicated. Lower part: Protein domains are indicated with different colors. GLA, triangle, $y$-carboxyglutamic acid-containing domain. EGF, trapezium, epidermal growth factor-like domain. Green box, promoter. The complete intracellular protein, and the circulating forms are depicted. The numbers of residues in the pre-pro-leader sequence $(n=60)$, in the circulating forms ( $n=406)$ and in the light ( $n=152)$ and heavy $(n=254)$ chains are indicated. The interchain disulphide bridge is also depicted (yellow bracket). 
apparently redundant and irreversible inhibition of FVIIa is also exerted by the serpin antithrombin (AT), ${ }^{33}$ and a substantial portion of FVIIa may be cleared through this relatively stable complex (FVIIa-AT), ${ }^{34}$ which circulates in plas$\mathrm{ma}$ at a concentration similar to that of FVIIa. FVII and FVIIa also bind the protein $\mathrm{C}$ receptor on endothelial cells (EPCR) with relevant affinity, but at present the pathophysiological significance of this interaction is unclear.

\section{Congenital factor VII deficiency}

Definition, prevalence and epidemiology

FVII deficiency was first described as a bleeding disorder by Alexander and colleagues ${ }^{13}$ and represents a model disease to understand the pathophysiology of recessively inherited coagulation deficiencies. Relevant findings on FVII deficiency are summarized on a historical time scale in Figure 1B, and some of the open issues are summarized in Table 2. Congenital FVII deficiency (OMIM 227500, ORPHA 327) is defined as a bleeding disorder associated with FVII coagulant activity below $50 \%$ of normal. However, this threshold includes asymptomatic heterozygotes for causative mutations and may comprise individuals homozygous for frequent FVII lowering single nucleotide polymorphisms (SNP). ${ }^{35}$ These subgroups substantially contribute to the belief that FVII deficiency is a mild bleeding disorder. ${ }^{36}$

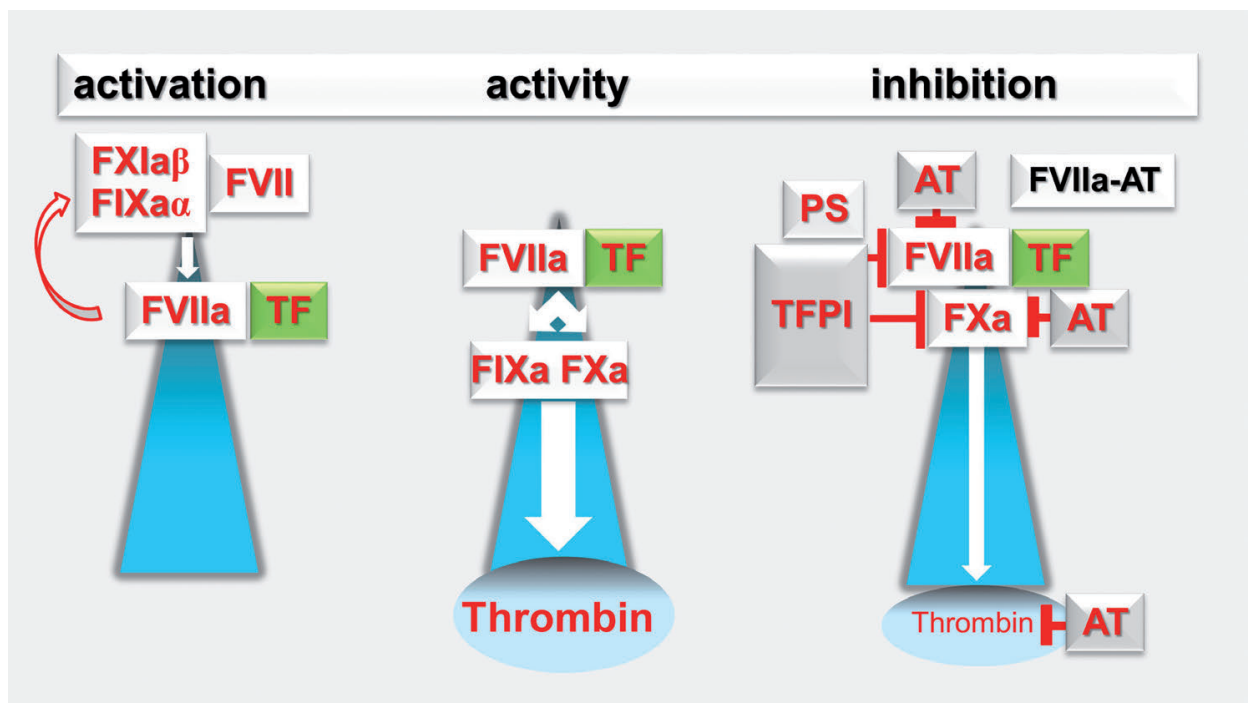

Figure 3. Schema showing factor VII activation, activity and inhibition (see text for specific information and references). TF: tissue

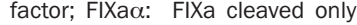
after Arg226; FIXaß: FIX cleaved after Arg191 and Arg226 (ref. ${ }^{24}$ ); AT: antithrombin; PS: protein S.

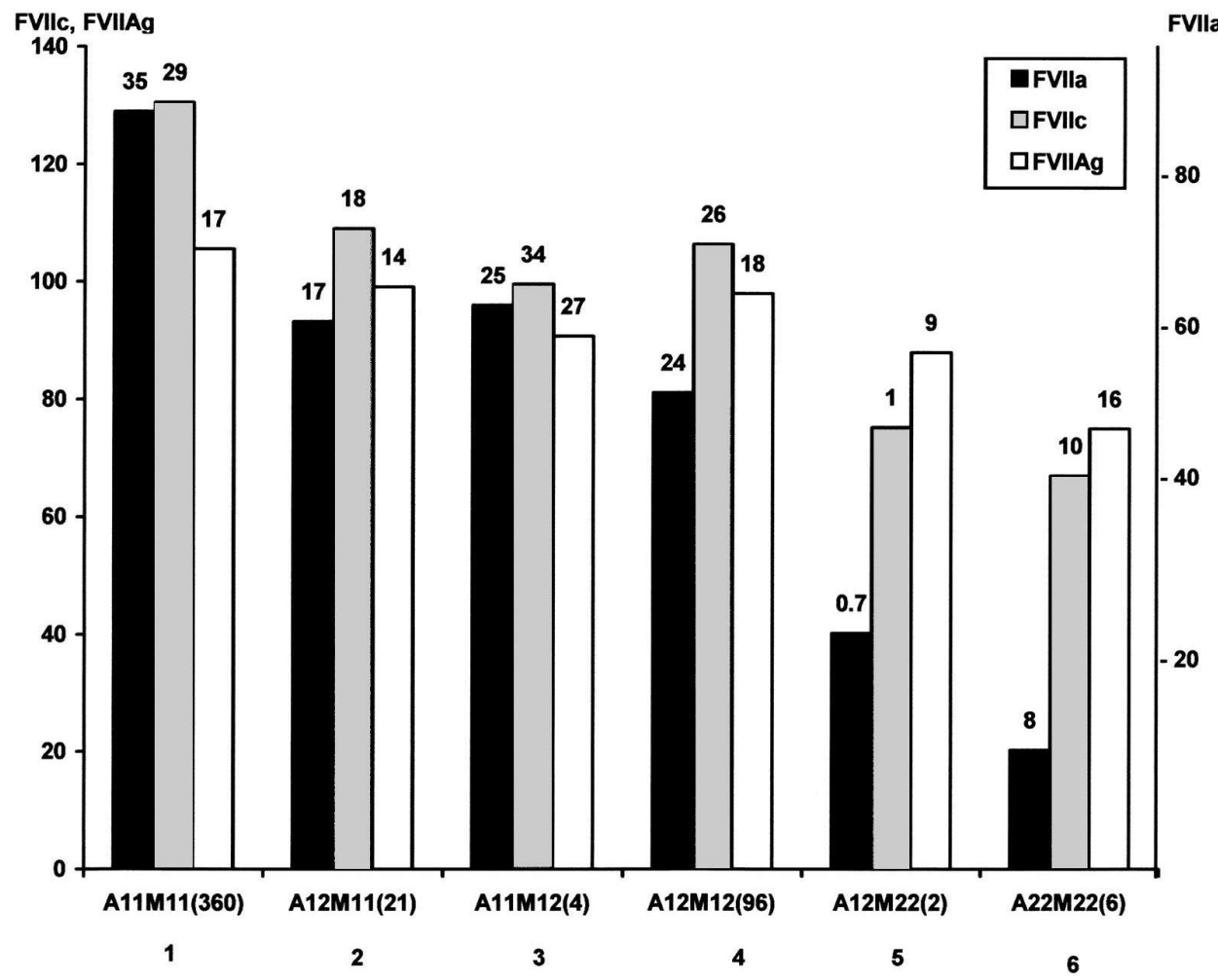

Figure 4. F7 genotype driven differences in FVIla, FVIIc and FVIIAg in the European population. Mean values of FVIla $(\mathrm{mU} / \mathrm{mL})$, FVIIc (\% of PNP), and FVIIAg (\% of PNP) in genotype groups determined by the promoter ( $5^{\prime} \mathrm{F} 7$ ins del) and missense 353(413)Arg/GIn polymorphisms. Standard deviation is reported above each column. The number of subjects is reported in parentheses. Significant differences, groups 1-6 $(P<0.001)$ : FVIlc: 1 vs. 2, 4, 6; 4 vs. 6 ; FVIla: 1 vs. 4,6 2 vs. $6 ; 4$ vs. 6 ; and FVIlag 1 vs. 4 , 6. Adapted from "Contribution of factor VII genotype to activated FVII levels. Differences in genotype frequencies between Northern and Southern European Populations". ${ }^{107}$ FVII: factor VII; FVIIc: FVII activity; FVIIAg: FVII antigen; PNP: pooled normal plas ma; ins: insertion; del: deletion 
FVII deficiency is believed to be very rare (one case in 500,000 individuals). ${ }^{36,37}$ The World Federation of Hemophilia ${ }^{38}$ estimates around 5,000 FVII-deficient individuals in the countries covered by this organization. However, the Italian Registry of Congenital Rare Bleeding Disorders $^{39}$ (RBD) reported 1,023 cases with FVII deficiency among the 2,178 patients registered. This figure, similar to that reported by the UK registry $(n=1.373),{ }^{38}$ suggests a prevalence only slightly lower than that of hemophilia B, at least in Italy (FVII deficiency, 1:59,000; haemophilia B, 1:67,000 individuals). Accordingly, FVII deficiency accounts for the most frequent RBD in most registries (36$49 \%){ }^{37,39}$ These data support the concept (Table 1) that FVII deficiency, including mild, moderate and severe forms, might be much more prevalent than previously reported. Large differences in prevalence, with variation reaching one order of magnitude, have been reported in those geographical areas where consanguineous marriages are frequent.

\section{Clinical picture}

The bleeding tendency in FVII deficiency varies from forms more severe than those seen in the hemophilias ${ }^{40}$ to very mild forms or asymptomatic cases. A simple classification of the clinical severity was proposed:10 i) severe forms (central nervous system [CNS] and/or gastrointestinal [GI] bleeding and/or hemarthrosis; ii) moderate forms (three or more symptoms other than CNS and/or GI bleeding and/or hemarthrosis); iii) mild forms (one or two symptoms, mostly muco-cutaneous, and other than CNS and/or GI and/or hemarthrosis).

In the International F7 Registry and the Seven Treatment Evaluation Registry (STER) ${ }^{41}$ that include 787 cases, $12 \%$ of individuals had a severe to very severe phenotype and three fourth of them bled within the first year of age (Table 4). About $20 \%$ of individuals with FVII deficiency suffer from a bleeding disorder that can be lifethreatening and/or be a major handicap. On the other hand, the most frequently observed patient cohort $(>50 \%)$ is characterized by muco-cutaneous types of bleeding: epistaxis (two thirds), gum bleeding (one third), easy bruising (one third), and menorrhagia (70\% of the females). In general, the bleeding tendency remains the same during the lifetime of the patient with the first bleeding event being a strong and independent predictor of the risk for the subsequent bleeding phenotype. ${ }^{41}$ Coinheritance of factor $\mathrm{V}$ Leiden enhances thrombin formation and is associated with a mild bleeding phenotype. ${ }^{42}$

Levels of FVIIc higher than $26 \%^{11,41,43}$ may have a nil or minimal clinical relevance in terms of spontaneous bleeding and subjects with FVIIc levels $<10 \%$ who remain asymptomatic most of their lives are not rare in being diagnosed during family studies or hemostatic screenings. . $^{10,11,35}$

Table 1. Distinctive features of coagulation factor VII (FVII), activated FVII, FVII deficiency, FVII levels and cardiovascular disease.

\begin{tabular}{|c|c|c|c|}
\hline FVII & FVII (FVlla) & FVII deficiency & FVII levels \\
\hline $\begin{array}{l}\text { Very low plasma } \\
\text { concentrations } \\
(0.5 \mu \mathrm{g} / \mathrm{mL})\end{array}$ & $\begin{array}{l}\text { First protease in the coagulation } \\
\text { cascade. } \\
\text { Lowest catalytic activity without } \\
\text { cofactor (TF). }\end{array}$ & $\begin{array}{l}\text { Highest prevalence among autosomally } \\
\text { recessive rare bleeding disorders }\end{array}$ & $\begin{array}{l}\text { High variability in human populations } \\
\text { High number of environmental } \\
\text { determinants }\end{array}$ \\
\hline $\begin{array}{l}\text { Short half-life } \\
2-4 \text { hours } \\
\text { Stable in plasma }\end{array}$ & $\begin{array}{l}\text { Half-life of FVIIa } \\
\text { and FVII similar (2-3 hours) } \\
\text { rFVIIa for replacement therapy }\end{array}$ & $\begin{array}{l}\text { Complete deficiency results in perinatal } \\
\text { mortality } \\
\text { High incidence of intracranial } \\
\text { bleeding (severe form) }\end{array}$ & $\begin{array}{l}\text { High proportion of variance } \\
\text { explained by } F 7 \text { gene variation } \\
\text { The genotype/phenotype relationship } \\
\text { is one of the most extensively } \\
\text { investigated among human genes }\end{array}$ \\
\hline $\begin{array}{l}\text { Conserved in all jawed } \\
\text { vertebrates }\end{array}$ & $\begin{array}{l}F 7 \text { polymorphisms are strong } \\
\text { predictors of FVIIa levels }\end{array}$ & $\begin{array}{l}\text { Wide variation of bleeding phenotype } \\
\text { in relation to modest FVII level variations }\end{array}$ & $\begin{array}{l}\text { Frequent FVII level- lowering alleles } \\
\text { with wide differences in human } \\
\text { populations }\end{array}$ \\
\hline $\begin{array}{l}\text { High similarity with } \\
\text { factor IX, factor X } \\
\text { and Protein C }\end{array}$ & $\begin{array}{l}\text { Very low amounts of FVIIa sufficient } \\
\text { to initiate coagulation } \\
\text { «Stable»FVIIa-AT complex }\end{array}$ & $\begin{array}{l}\text { Homozygous FVII-lowering alleles } \\
\text { mimic Mendelian heterozygous } \\
\text { deficiency }\end{array}$ & $\begin{array}{l}\text { High/low levels associated with } \\
\text { predisposition/ protection } \\
\text { towards/from cardiovascular disease }\end{array}$ \\
\hline
\end{tabular}

FVII: factor VII; FVIIa: activated FVII; rFVIIa: recombinant FVIIa;TF; tissue factor; AT: serpin antithrombin; $F 7$ : factor VII gene.

Table 2. Some open issues in factor VII (FVII) protein and F7 genetics, FVII deficiency, FVII levels and cardiovascular disease.

\begin{tabular}{|c|c|c|}
\hline FVII / F7 & FVII deficiency & $\begin{array}{l}\text { F7 gene variation } \\
\text { cardiovascular disease }\end{array}$ \\
\hline $\begin{array}{l}\text { Mechanisms underlying } \\
\text { FVIIa levels }\end{array}$ & $\begin{array}{l}\text { Residual FVII concentration predicting the most } \\
\text { severe symptoms is still puzzling. } \\
\text { Residual FVII concentration preventing spontaneous } \\
\text { bleeding is difficult to define. }\end{array}$ & $\begin{array}{l}\text { Population features causing large differences in the } \\
\text { prediction of cardiovascular disease risk by } F 7 \text { genotypes }\end{array}$ \\
\hline $\begin{array}{l}\text { Decryption of TF for FVIIa } \\
\text { binding and catalytic activity }\end{array}$ & $\begin{array}{l}\text { Short plasma half life of FVII/rFVIIa for therapeutic } \\
\text { purposes. } \\
\text { Discrepancy between rFVIIa pharmacokinetic and } \\
\text { pharmacodynamic data }\end{array}$ & $\begin{array}{l}\text { Impact of FVII-lowering alleles in the protection } \\
\text { from cardiovascular disease }\end{array}$ \\
\hline $\begin{array}{l}\text { Physiological balance between } \\
\text { FVIIa inhibitors }\end{array}$ & $\begin{array}{l}\text { Impact of FVII-lowering alleles in increasing the } \\
\text { clinical penetrance of pathological } F 7 \text { gene lesions }\end{array}$ & $\begin{array}{l}\text { Impact of FVII-increasing alleles in the predisposition } \\
\text { toward specific cardiovascular disease forms }\end{array}$ \\
\hline
\end{tabular}

FVII: factor VII; FVIIa: activated FVII; rFVIIa: recombinant FVIIa; TF: tissue factor; $F 7$ : factor VII gene. 
However, the therapeutic thresholds conferring protection from traumatic or post-operative bleeds are still a matter of debate. ${ }^{44,45}$ Surgical bleeding has been reported in $15-24 \%$ of cases $^{42,45}$ with FVIIc $<7 \%{ }^{42}$ Bleeds in the first post-operative day ${ }^{46}$ are particularly frequent if the bleeding disorder was not diagnosed before, and are mostly reported during orthopedic procedures, ${ }^{46}$ a major hemostatic challenge. Presenting symptoms as post-circumcision bleeds and hemorrhage from the umbilical stump frequently herald a severe disease form.

\section{Diagnosis}

The spectrum of bleeding symptoms is wide, involves both males and females, can start after birth and may occur at any age. The most important predictors of bleeding risk, familial and personal histories, can be silent as observed in diseases with recessive inheritance. The relevance of the gynecological and obstetric histories are discussed in a dedicated paragraph.

The laboratory workup ${ }^{47}$ performed after a bleeding episode or during a family screening includes routine screening assays (prothrombin time [PT], activated partial thromboplastin time [aPTT]), followed by FVIIc measurement, which is necessary to confirm the diagnosis. Evaluation of FVIIc is determined with a one-stage assay adding diluted plasma samples to FVII-deficient plasma and thromboplastin as the source of TF. The accuracy of FVIIc assays is related to the sensitivity of the thromboplastin reagent and to the quality of the FVII-deficient plasma and of the calibrators. The most suitable activators are the human placenta-derived and the recombinant preparations ${ }^{47}$ that are also recommended to monitor the treatment with rFVIIa. ${ }^{25} \mathrm{New}$ chromogenic or fluorogenic assays for FVIIa are available for research purposes and to monitor treatment with rFVIIa. ${ }^{48}$

The sensitivity of the FVIIc assay to levels below 2\% may be poor, with negative implications for the accurate definition of the relationship between FVII levels and bleeding phenotypes (Table 1), as well as between genotype and phenotype. A low assay sensitivity may explain some inconsistencies such as the paradoxical observation of asymptomatic cases with low FVII levels. Furthermore, severe bleeding is sporadically observed in individuals with moderately reduced levels of FVII. The combination of the low assay sensitivity with the minimal amount of FVIIa-TF complex needed to trigger coagulation does not permit one to efficiently differentiate clinical phenotypes. As a consequence, in FVII deficiency a variety of bleeding phenotypes are observed in the presence of apparently modest differences in FVIIc levels (Table 1). In summary, the clotting tests do not always predict the degree of bleeding tendency in the single individual.

The presence of the FVII protein (FVII antigen [FVIIag]) can be determined by enzyme-linked immunosorbent assays or immune-turbidimetric assays, using monoclonal epitope-specific antibodies. ${ }^{47}$ The FVIIag assay ${ }^{47}$ does not predict the bleeding tendency, but does allow one to distinguish between type I (quantitative defects, with decrease of both FVIIc and FVIIAg), and type II defects (qualitative defects, with low FVIIc and normal or reduced levels of FVIIAg), and may help to clarify the different mutational mechanisms.

\section{Molecular genetics}

The key findings are summarized on a historical time scale in Figure 1B, and the main findings in individuals with FVII deficiency are shown in Table 3. The functional characterization of protein variants in plasma was carried out in seminal studies ${ }^{49}$ well before the genetic characterization of FVII deficiencies. The first F7 gene mutations in FVII deficiency were reported in the $\mathrm{UK}^{50}$ and Italian populations, and more than 1,000 genetic diagnoses in several countries are reported in the International Registry on FVII deficiency $\left(\right.$ IRF7) ${ }^{10}$ and the Greifswald Registry. ${ }^{11}$ Mutations and residual FVII levels have been presented in databases. ${ }^{51}$ The recent EHAD database ${ }^{12}$ (http://www.umd.be/F7/W_F7/index.html) includes 221 unique variants identified in 728 individuals, of great help for the evaluation of $F 7$ mutations found during genetic counseling and diagnosis, including prenatal diagnosis. ${ }^{5}$

F7 mutations have been detected by sequencing coding, splicing and in promoter regions in the vast majority of patients. High throughput genomic sequencing will help in the case no mutations are found. ${ }^{52}$ Cases with severe symptoms are virtually all homozygous or doubly heterozygous for F7 mutations. Symptomatic mutations impairing vitamin $\mathrm{K}$ metabolism, and thus posttranslational modification of GLA residues, have been found to cause combined vitamin K-dependent clotting factor deficiency that includes an abnormal FVII biosynthesis and low FVIIc levels.

As reported in registries ${ }^{11}$ and databases, ${ }^{12}$ single nucleotide variants are the most common type of gene defect (around 90\%), and include a large proportion (between two thirds and three quarters) of missense mutations.

Numerous missense mutations have been found in the homozygous condition, related to geographical, ethnic and mutational pattern features. Clusters of homozygotes often indicate genetic isolates or ethnic customs favoring consanguinity (see below).

Since they have been well presented in databases, ${ }^{12}$ we shall briefly comment on a few of them.

The severe Gln100(160) $\operatorname{Arg}^{53,54}$ and the moderate/mild Ala294(354)Val ${ }^{55,56}$ are prevalent in Northern Europe. The frameshift mutation in the last carboxyl terminal codons (Pro404(464)Hfs) is very prevalent in cis with the Ala294(354)Val missense change and causes a 28 residueselongated FVII molecule. This moderate to severe and combined variant is frequent in Central Europe and especially in Slovakia. ${ }^{10}$ The mild Gly331(391)Ser mutation is prevalent in the gulf of Naples, Italy, as well as in other countries. ${ }^{57}$ Other mild/asymptomatic changes, the Arg304(364)Gln $\ln ^{50}$ Cys310(370)Phe/Ser and Thr359(419)Met substitutions, have been found in several populations, suggesting recurrent nucleotide changes at a CpG site. The frequent Arg304(364)Gln is also characterized by discrepant FVII activity findings depending on the thromboplastin reagent. ${ }^{49}$

Splicing mutations are not rare, ${ }^{52}$ and the homozygous splicing mutation IVS7 $+5 \mathrm{~g}>\mathrm{a}$, relatively frequent in Italy, has been used for cellular $r^{58,59}$ and animal ${ }^{60}$ models of gene therapy.

F7 deletions are also not rare and together with duplications, insertions and indel rearrangements represent about $10 \%$ of all genetic lesions. ${ }^{12}$ However, large and extended deletions have not been described in homozygous individuals. Differently from hemophilia $\mathrm{A}$ and $\mathrm{B}$, individuals with complete FVII deficiency might die perinatally or 
Table 3. Overview of molecular genetics findings in factor VII deficiency. Molecular genetics of FVII deficiency

Genetic diagnosis

Sanger sequencing of exons and splicing junctions in $>1,000$ individuals with FVII deficiency

Next-generation sequencing in a few individuals

Phenotypic assays do not define specific genetic defects*

No highly frequent gene lesions

Large heterogeneity of genetic causes ( $\mathrm{n}>300$ different mutations)

Geographical/ethnic clustering of identical-by-descent mutations $(n>15)$

Several recurrent mutations in different populations

\begin{tabular}{ll}
$\begin{array}{ll}\text { Mutation zygosity and } \\
\text { disease severity }\end{array}$ & $\begin{array}{l}\text { Severe deficiencies caused by compound heterozygous/homozygous mutations } \\
\text { Increased prevalence of homozygotes in genetic isolates/consanguineous marriages } \\
\text { Otherwise asymptomatic heterozygous variants associated with frequent FVII-lowering single nucleotide } \\
\text { polymorphism in mild deficiencies }\end{array}$ \\
\hline Mutation type frequency & Missense $>>$ Small deletions $>$ Splicing $>$ Nonsense $>$ Large deletions (not reported in homozygosity) \\
Recombinant expression & Numerous variants expressed after site directed mutagenesis \\
& A few purified protein variants \\
Translational read through over premature termination codons \\
Gain-of-function premature termination codon
\end{tabular}

*The asymptomatic Arg364Gln is detectable by using different thromboplastins ${ }^{59}$. Small deletions include also insertions and indels. FVII: factor VII.

Table 4. Management of factor VII deficiency using recombinant factor VII (synopsis of the STER study data).

\begin{tabular}{|c|c|c|c|c|}
\hline Clinical Context & $\begin{array}{l}\text { Treatments } \\
\text { (n) }\end{array}$ & $\begin{array}{l}\text { Treatment days } \\
\text { Median, range }\end{array}$ & $\begin{array}{c}\text { Total dose of rFVlla } \\
\text { Median, range ( } \mathrm{pg} / \mathrm{kg} \text { of body weight) }\end{array}$ & Outcome \\
\hline Spontaneous bleeding & 79 & $1(1-14)$ & $60(10-3,600)$ & $\begin{array}{l}3 \text { rebleeding } \\
1 \text { inhibitor }\end{array}$ \\
\hline Major surgery^$^{\wedge}$ & 24 & $3.5(1-16)$ & $31.9(12-120)$ & $\begin{array}{c}3 \text { bleeding } \\
\text { (orthopaedic surgery) }\end{array}$ \\
\hline Minor surgery and invasive procedures & 29 & $1(1-4)$ & $20(7.2-510)$ & 1 inhibitor \\
\hline Prophylaxis ${ }^{\S}$ & $\begin{array}{c}31 \\
18(3 / \text { week }) \\
13(2 / \text { week })\end{array}$ & 3/week or 2/week & $\begin{array}{l}30 \text { ( } 3 \text { per week) } \\
24 \text { (3 per week) }\end{array}$ & $\begin{array}{l}\text { Partly effective in one } \\
\text { case in each of the } \\
\text { two arms }\end{array}$ \\
\hline
\end{tabular}

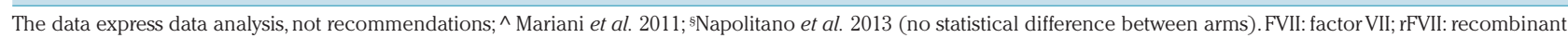
FVII; STER: Seven Treatment Evaluation Registry.

shortly after birth due to severe hemorrhage. ${ }^{5}$ Complete FVII deficiency causes perinatal mortality in "knockout" mice, in which the presence of a trace amount of FVII $(0.7 \%)$ seems sufficient for survival with symptoms. ${ }^{61}$ Several cases with heterozygous combined FVII and FX deficiency, due to large deletions within the terminal end of chromosome 13, have been reported. ${ }^{6}$

Recombinant expression after site-directed mutagenesis has been performed for a number of mutations detected in patients, which permits one to investigate the molecular bases of the deficiency. Recombinant studies of the rare and potentially null homozygous nonsense mutations support the notion that gain-of-function and translational readthrough over premature stop codons may prevent truly null conditions and may contribute to the unexpectedly variable bleeding phenotype in individuals homozygous for F7 nonsense changes. ${ }^{63}$ Whereas life-threatening symptoms have been associated with the p.Ser52(112)X, moderate bleeding was observed in p.Cys82 (132)X homozygotes. The Arg402(462)X change permits the secretion of a small amount of protein with gain-of-function features, causing a mild phenotype paradoxically associated with a "null" mutation. ${ }^{64}$

Chimeric fluorescent FVII molecules have also been constructed to investigate intracellular processing of variants, and chemical chaperones have been used to stimu- late their secretion. ${ }^{54}$ The FVII protein has been purified and biochemically characterized for very few variants, among these the frequent Arg304(364)Gln ${ }^{50}$ and Ala294(354) $\mathrm{Val}^{55}$ changes, as well as the severe Gln160 Arg ${ }^{33}$ and the activation sequence Val154(214)Gly ${ }^{65}$ changes. These laborious experiments provided strong support for the understanding of the mild or severe coagulation phenotypes in vivo and for FVII altered expression and properties.

The homozygous conditions for polymorphisms predicting lower FVII levels might not be pathogenic but mimic Mendelian heterozygous FVII deficiency ${ }^{35}$ (Table 1), which frequently leads to the request for clotting defect diagnosis in pre-surgical screenings, and generates confusion in estimating the incidence of inherited FVII deficiency (see dedicated section). In light of their effects on lowering FVII plasma levels, these variants might contribute to pathogenicity of co-inherited variants. ${ }^{52}$ As a matter of fact the frequencies of the FVII-lowering alleles were significantly higher ${ }^{51}$ in the FVII-deficient individuals tested than in controls, suggesting that the presence of these alleles may have increased, through increased clinical significance (Table 2), the likelihood of identifying "causative" F7 gene lesions. Genotyping of these frequent variants would be especially useful for the interpretation of mild and moderate FVII deficiency. 


\section{Replacement therapy and prophylaxis}

Replacement therapy (RT) options are determined by: the rarity of the disorder; the availability and supply of products and the economic and geographical factors. These include: i) recombinant FVIIa (rFVIIa), ii) plasmaderived FVII (pdFVII), iii) fresh frozen plasma (FFP) and prothrombin complex concentrates (PCC). In the STER prospective trial (comprising $312 \mathrm{RT}$ ) most therapies were carried out with rFVIIa (78\%), the remaining with FFP $(10 \%)$, pdFVII concentrates $(10 \% \%)$ and PCC $(2 \%)$.

Based on the modest catalytic activity of FVIIa in the absence of TF, the therapeutic/prophylactic use of FVIIa and rFVIIa (initially proposed for bleeding diathesis other than FVII deficiency) represents a therapeutic milestone ${ }^{8}$ and distinguishes replacement therapy in FVII deficiency from that in the other coagulation defects (Table 1). Although in FVII deficiency rFVIIa is employed (Figure $1 \mathrm{~A}$ ) at doses (Table 3 ) much lower than those needed for patients with FVIII inhibitors, supraphysiological FVIIa concentrations are also produced in plasma of FVII deficient subjects.

It is still a matter of debate whether rFVIIa acts through the binding with TF, provided by microparticles shed into the circulation following diverse stimuli, or binds at high concentration ${ }^{66}$ to anionic phospholipids exposed on activated platelets, thus directly activating FX to FXa. FXa would in turn generate thrombin, bypassing the tenase complex. It is tempting to speculate that the physiological FVIIa-TF function (Figure 3) prevails at the rFVIIa doses used in FVII deficiency and in the presence of normal FVIII levels. rFVIIa easily diffuses into the extravascular spaces where it could be retained for extended time periods. As supported by pharmacokinetic studies, ${ }^{67} \mathrm{rFVII}$ prolongs its pharmacological effects at low concentration, in accordance with the hypothesis of physiological binding to TF.

rFVIIa has a very good safety-to-efficacy ratio. ${ }^{46}$ Oneday therapy with 'intermediate' doses of rFVIIa can be effective and safe for the treatment of most of spontaneous bleeds as well as for minor surgery and invasive procedures (Table 3). Replacement with rFVIIa is also effective to prevent bleeding in major surgical procedures. ${ }^{46}$

The large volume of the infusions and the limited availability make pd-FVII concentrates less appealing. Currently, the average pd-FVII dosages used are 15-20 IU/kg for mucosal bleeding, and 30-40 IU/kg for severe or life-threatening hemorrhages.

Although FFP is easily available in developing countries, its effectiveness is limited owing to the high risk of fluid overload and the consequent need for slow infusions.

In the case of mild mucosal bleeds (epistaxis, mild menorrhagia) tranexamic acid and hormones are currently considered.

Anti-fibrinolytic agents are contraindicated in hematuria, and may trigger thrombosis in association to PCC.

Prophylaxis is warranted for patients with the most severe bleeding picture and should be prescribed from childhood or soon after the first bleeding event. ${ }^{45,68}$ Effective prophylaxis schedules have been reported for rFVIIa $^{68,69}$ and pdFVII concentrates. ${ }^{70}$

\section{Treatment complications}

Inhibitors to FVII are a rare $(1-2 \%)^{71}$ complication that occurs mainly in severely deficient patients, particularly in children younger than 1 year on prophylaxis. We observed only high responders ( $>5 \mathrm{BU}$ Bethesda Unit $)^{71}$, and in the presence of a high-titer inhibitor to FVII treatment becomes a problem. ${ }^{71}$

At variance with the homologous deficiency of FIX ( $F 9$, $\mathrm{HB}$ ), complete homozygous gene deletions that predispose to FIX inhibitors have never been detected in FVII deficiency (Table 1), ${ }^{5,12}$ and FVII inhibitors have never been shown to be complicated by allergic reactions.

Paradoxically, a dozen of cases with FVII deficiency and thrombosis have been reported. Surgical interventions and/or replacement therapies had a close temporal relationship with thrombotic episodes, but apparently spontaneous events were also reported. . $8,72^{2}$ Different replacement therapies were associated with the thrombotic events: PCC (three cases), rFVIIa (three cases), pdFVII (two cases), FFP (one case), no replacement (three cases). ${ }^{72}$ This suggests that FVII deficiency does not seem to offer protection from strong thrombosis risk factors such as surgery/high dose radiotherapy.

\section{Women with factor VII deficiency}

Autosomally transmitted RBD occur as frequently in women as in men, but women may experience more bleeding than men because gynecological and obstetric challenges to hemostasis add an important burden to the background bleeding related to the hemostatic defect. Menstruation and ovulation are associated with an increased risk of bleeding, as are pregnancy and delivery. ${ }^{73}$ While in normal and heterozygous women FVII plasma levels rise during pregnancy, no such increase is observed in women with a severe homozygous deficiency. As a consequence, symptomatic women with FVII deficiency may continue to bleed during pregnancy and postpartum. In a large study (234 women with FVII deficiency) ${ }^{74}$ menorrhagia during the reproductive age occurred in half of the cases, and in $12 \%$ represented the first bleed. Further, frequent gynecological problems, such as uterine fibroids, were diagnosed earlier because of the hemostatic defect. Although FVIIc was an important predictor of gynecological bleeding, other determinants including endocrine pathologies may also play a role.

For severe menorrhagia, management has been moved from hemostatic agents like tranexamic acid, oral contraceptives and intra-uterine devices, to replacement therapy and prophylaxis with effective single- or multiple-dose schedules. ${ }^{6,77,74}$ This will hopefully change clinical practice that, until recently, included surgical approaches such as endometrial ablation or hysterectomy.

\section{Therapeutics in development}

The first attempts to improve rFVIIa activity through mutagenesis, or its half-life in plasma by glycoPEGylation, have increased FVII antigenicity. Longer-acting FVIIa has been tested in different recombinant preparations, which are currently in clinical trials (reviewed in Menegatti et al. ${ }^{75}$ : i) addition of a c-terminal peptide ${ }^{76}$ potentially suitable for subcutaneous administration that led to prolonged pharmacodynamics effects, ii) an Fc receptor-fused rFVIIa that displayed a 5-fold longer plasma half-life and iii) an albumin-fused rFVIIa molecules that showed improved features compared to rFVIIa (2- to 3-fold longer half-life and 4- to 8-fold lower clearance) in patients with congenital FVII deficiency. ${ }^{77}$ Recently, an engineered albu- 
min-fused rFVIIa molecule showed enhanced transcellular transport upon intranasal delivery and extended plasma half-life in transgenic mice. ${ }^{78}$

The development of non-substitutive therapy for the hemophilias, such as the use of anti-antithrombin RNA interference or of aptamer and monoclonal antibodies directed against TFPI, have raised expectations for improvement of the quality of life in individuals with FVII deficiency. ${ }^{75}$

Based on adeno-associated viral-mediated expression of $\mathrm{FVII}^{79}$, gene therapy has produced sustained correction of severe FVII deficiency in dogs. In addition, gene therapy using FVIIa, inserted into the same viral vector, could also be used to treat congenital FVII deficiency with lower vector doses, which increases the chance of efficient and long term expression of the transgene. Small engineered RNA have also been used as an approach of personalized gene therapy to correct a human FVII splicing mutation in mice. ${ }^{59}$

\section{Factor VII levels, F7 genotypes and cardiovascu- lar disease}

Several findings have created interest and still lead to an intense investigation on the role of FVII in cardiovascular disease (Figure 1B). Exposure of TF to blood in (coronary) artery disease, and especially plaque rupture, may favor FVIIa-TF complex formation. Further, lipids are important components of atherosclerosis and determinants of FVII

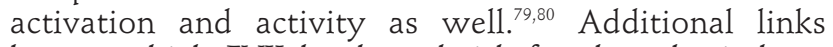
between high FVII levels and risk for thrombosis have been suggested ${ }^{11}$ by finding that the TF-FVIIa-Xa complex activates FVIII before coagulation amplification and that heparanase increases generation of FXa by the FVIIa-TFcomplex. ${ }^{82}$ Furthermore, the FVIIa-TF complex is believed to mediate non-hemostatic functions in diverse biological processes, such as angiogenesis, inflammation, atherosclerosis and vascular and cardiac remodeling, by activating signaling pathways (reviewed in D'Alessandro et al. ) $^{84}$ through FVIIa-integrin binding and PAR2 cleavage. ${ }^{85}$

The F7 promoter may respond to a number of metabolic components, and FVIIc levels are associated with several environmental factors linked to atherosclerosis i.e., body mass index, dietary fat intake, plasma lipids and particularly triglyceride concentration.

Age- and sex-related variations in FVII levels add complexity to the investigation of clinical correlates. FVII levels were found to increase with age and to be significantly lower in women than men at younger ages. Postmenopausal women displayed the highest levels, except when undergoing hormone replacement therapy. ${ }^{86}$ This conundrum of environmental factors interacts with the F7 gene variation.

\section{Factor VII levels and F7/genome wide genotypes}

FVII levels show ample variation in the normal population and have a substantial heritable component, also in relation to polymorphisms ${ }^{15}$ (Figure 4). Missense, ${ }^{87}$ repeat number variation, ${ }^{58}$ insertion/deletion ${ }^{22}$ and $\mathrm{SNP}^{23}$ were found to be associated with FVIIc, FVIIa and FVIIag levels (Figure 4) through epigenetic, transcription, biosynthesisor stability-mediated mechanisms. Whereas twin studies ${ }^{88}$ estimated about $60 \%$ of genetic-associated level of variance in plasma, the $F 7$ locus variation accounted for up to
$40 \%$ of variance. Genotype effects, perhaps stronger on FVIIa than on FVIIag (Figure 4), ${ }^{15}$ might modulate the response to environmental stimuli and the sex-dependent regulation..$^{89}$ Serum phospholipids were found to be strong and F7 genotype-associated FVIIa determinants. ${ }^{90}$

The number of F7 single SNP was substantially increased by highthroughput $F 7$ gene sequencing, which enabled very informative $F 7$ population studies. ${ }^{91}$ Genome-wide association studies (GWAS) confirmed ${ }^{14,92}$ the strong association between FVII levels and F7 gene variation..$^{93}$ Importantly, GWAS have detected a number of genomic regions associated with FVII levels (GCKR, ADH4, MS4A6A, PROCR, APOA5, HNF4A, REEP3JMJD1C, JAZF1-AS1, MLXIPL and XXYLT1), ${ }^{14,92}$ that could explain an additional one fifth of the FVII variance in plasma levels and are also, in part, associated with lipids which in turn modulate FVII activity. These gene-based association scan initiatives have been established in several populations. ${ }^{94}$ Overall, this picture defines one of the most extensively investigated relationship between genotypes and multiple quantitative phenotypes (FVIIc, FVIIag and FVIIa) (Table 1).

\section{Levels, genotypes and cardiovascular disease}

The Northwick Park Heart Study investigators were the first to report that high FVII levels were predictors of death due to coronary disease, ${ }^{16}$ and a number of studies confirmed this observation in different populations by also evaluating FVIIa levels. ${ }^{95}$

Recent investigations on the level of the FVIIa-AT complex, which may reflect levels of FVIIa as well its interaction with TF, indicated that higher complex concentrations were associated with increased mortality in the Cardiovascular Health Study. ${ }^{96}$ In patients with stable coronary artery disease (Verona Heart Study) higher FVIIaAT complex levels were associated with increased cardiovascular mortality and increased thrombin and FXa generation, ${ }^{97}$ particularly in the coagulation initiation phase. ${ }^{98}$ However, in small groups of patients with unstable angina, acute myocardial infarction ${ }^{99}$ or post-infarction ${ }^{80}$ FVIIa levels were not higher than in controls. High plasma FVIIag levels were associated with failure of thrombolytic therapy in patients with myocardial infarction. ${ }^{100}$ Elevated levels of FVII have not been consistently associated with venous thromboembolism. ${ }^{101}$

The influence of F7 genotypes on the hemostatic balance and on the susceptibility to cardiovascular disease has been extensively investigated in several large cohorts of patients in relation to both myocardial infarction and stroke. F7 polymorphisms with an opposite effect on FVIIa levels may positively or negatively modulate the risk of $\mathrm{MI}$ in males with advanced coronary artery disease, ${ }^{18}$ and some FVII genotypes may protect against myocardial infarction $^{17}$ by affecting transcription levels and reducing protein functional activity. The modulation of stroke risk in atrial fibrillation by F7 genotypes may follow a similar scheme $e^{102}$ and recently, in a meta-analysis of several GWAS $^{14}$ variations in FVII-related genes and FVIIc levels were associated with a risk of the incidence of ischemic stroke in the general population. The physiological effects of FVII lowering alleles may represent a natural model for anticoagulation; in fact F7 polymorphisms were shown to play a role in determining the initial response to warfarin $^{103}$ and influencing the risk of thrombosis in patients with essential thrombocythemia ${ }^{104}$. 
Large haplotype studies confirmed that the F7 gene strongly influences FVII levels, but associations with coronary artery disease and FVII level were inconsistent. ${ }^{105}$ Variable genetic, environmental and atherogenic risk factors in different populations may explain this discrepancy (Table 2). The frequencies of F7 genotypes predicting lower FVII levels are higher in Caucasians and much lower in Chinese and Malays populations. On the other hand, the distribution of these F7 genotypes covaries across populations in Europe with the rate of myocardial infarction mortality, being higher in countries at low risk. ${ }^{106}$

The most recent meta-analysis of large studies ${ }^{14}$ appears to be consistent with positive and potentially clinically important causal effects of FVIIc levels, both on coronary artery disease and venous thromboembolism. However, several open issues remain (Table 2) and the usefulness of FVIIc and FVIIa evaluation in patients with cardiovascular risks is still unclear.

\section{Conclusive remarks}

In summary, in the 70 years since FVII investigation started, research has been particularly intense (Figure 1), and provided excellent examples at the basic science and translational levels. The multidisciplinary approaches have spanned structural biology, biochemistry, recombinant protein biotechnology, molecular and population genetics, pharmacology, clinics and epidemiology, and encompassed various areas of hematology, hemostasis and thrombosis.

The large number of studies on FVII have not only served to substantially improve our knowledge on FVII biology and related phenotypes and to improve the quality of life of the individuals with FVII deficiency, but also to train three generations of scientists in different fields.

\section{Disclosures \\ Pfizer Research Grant}

\section{Contributions}

FB and GM wrote the Manuscript

\section{Acknowledgments}

The authors express their gratitude to Prof. Peter Lydyard (emeritus at UCL London, UK and associate at Georgia University, Tbilisi Georgia) for his very helpful text revision and Dr Barbara Lunghi for her help in the selection of references.

\section{References}

1. Nemerson Y, Esnouf MP. Activation of a proteolytic system by a membrane lipoprotein: mechanism of action of tissue factor. Proc Natl Acad Sci U S A. 1973;70(2):310314.

2. Gajsiewicz JM, Morrissey JH. Structurefunction relationship of the interaction between tissue factor and factor VIIa. Semin Thromb Hemost. 2015;41(7):682690.

3. McVey JH. The role of the tissue factor pathway in haemostasis and beyond. Curr Opin Hematol. 2016;23(5):453-461.

4. Ansari SA, Pendurthi UR, Rao LVM. Role of cell surface lipids and thiol-disulphide exchange pathways in regulating the encryption and decryption of Tissue Factor. Thromb Haemost. 2019;119(6):860-870.

5. McVey JH, Boswell EJ, Takamiya O, et al. Exclusion of the first EGF domain of factor VII by a splice site mutation causes lethal factor VII deficiency. Blood 1998;92(3):920926.

6. Lawson JH, Kalafatis M, Stram S, Mann KG. A model for the tissue factor pathway to thrombin. I. An empirical study. Biol Chem. 1994;269(37):23357-23366.

7. Zelaya H, Rothmeier AS and Ruf W. Tissue factor at the crossroad of coagulation and cell signaling. J Thromb Haemost. 2018;16(10):1941-1952.

8. Hedner U, Glazer S, Pingel $\mathrm{K}$, et al. Successful use of recombinant factor VIIa in a patient with severe hemophilia A during synovectomy. Lancet. 1988;2(8621):1193.

9. O'Hara PJ, Grant FJ, Haldeman BA, et al. Nucleotide sequence of the gene coding for human factor VII, a vitamin K-dependent protein participating in blood coagulation. Proc Natl Acad Sci U S A. 1987;84(15):51585162.

10. Mariani G, Herrmann FH, Dolce A, et al. International Factor VII Deficiency Study Group. Clinical phenotypes and factor VII genotype in congenital factor VII deficiency. Thromb Haemost. 2005;93(3):481-487.
11. Herrmann FH, Wulff K, Auerswald G, et al. Greifswald Factor FVII Deficiency Study Group. Factor VII deficiency: clinical manifestation of 717 subjects from Europe and Latin America with mutations in the factor 7 gene. Haemophilia. 2009;15(1):267-280.

12. Giansily-Blaizot M, Rallapalli PM, Perkins SJ, et al. The EAHAD blood coagulation factor VII variant database. Hum Mutat. 2020;41(7):1209-1219.

13. Alexander B, Goldstein R, Landwehr G, Cook CD. Congenital SPCA deficiency: a hitherto unrecognized coagulation defect with hemorrhage rectified by serum and serum fractions. J Clin Invest. 1951;30(6): 596-608.

14. de Vries PS, Sabater-Lleal M, Huffman JE, et al. A genome-wide association study identifies new loci for factor VII and implicates factor VII in ischemic stroke etiology. Blood. 2019;133(9):967-977.

15. Bernardi F, Marchetti G, Pinotti M et al. Factor VII gene polymorphisms contribute about one third of the factor VII level variation in plasma. Arterioscler Thromb Vasc Biol. 1996;16(1):72-76.

16. Meade TW, Mellows S, Brozovic M, et al. Haemostatic function and ischaemic heart disease: principal results of the Northwick Park Heart Study. Lancet. 1986;2(8506): 533-537.

17. Iacoviello L, Di Castelnuovo A, De Knijff P, et al. Polymorphisms in the coagulation factor VII gene and the risk of myocardia infarction. N Engl J Med. 1998;338(2):79 85

18. Girelli D, Russo C, Ferraresi P, et al. Polymorphisms in the factor VII gene and the risk of myocardial infarction in patients with coronary artery disease. N Engl J Med. 2000;343(11):774-780

19. Hagen FS, Gray CL, O'Hara P, et al. Characterization of a cDNA coding for human factor VII. Proc Natl Acad Sci U S A. 1986;83(8):2412-2416.

20. Arbini AA, Pollak ES, Bayleran JK, High KA, Bauer KA. Severe factor VII deficiency due to a mutation disrupting a hepatocyte nuclear factor 4 binding site in the factor
VII promoter. Blood. 1997;89(1):176-82

21. Barbon E, Pignani S, Branchini A, Bernard F, Pinotti M, Bovolenta M. An engineered tale-transcription factor rescues transcription of factor VII impaired by promoter mutations and enhances its endogenous expression in hepatocytes. Sci Rep. 2016;6:28304.

22. Marchetti G, Patracchini P, Papacchini M Ferrati M, Bernardi F. A polymorphism in the $5^{\prime}$ region of coagulation factor VII gene (F7) caused by an inserted decanucleotide. Hum Genet. 1993;90(5):575-576.

23. van't Hooft FM, Silveira A, Tornvall P, et al. Two common functional polymorphisms in the promoter region of the coagulation factor VII gene determining plasma factor VII activity and mass concentration. Blood. 1999;93(10):3432-3441.

24. Misenheimer TM, Kumfer KT, Bates BE, Nettesheim ER, Schwartz BS. A candidate activation pathway for coagulation factor VII. Biochem J. 2019;476(19):2909-2926.

25. Morrisey JH, Macik BG, Neuenschwander PF, Comp PC. Qantitation of activated factor VII levels in plasma using a tissue factor mutant selectively deficient in promoting factor VII activation. Blood. 1993;81(3):734744.

26. Sorensen AB, Tuneew I, Anders Svensson $\mathrm{L}$, et al. Beating tissue factor at its own game: Design and properties of a soluble tissue factor-independent coagulation factor VIIa. J Biol Chem. 2020;295(2):517-528.

27. Davidson CJ, Hirt RP, Lal K, et al. Molecular evolution of the vertebrate blood coagulation network. Thromb Haemost. 2003;89 (3):420-428.

28. Osterud B, Rapaport SI. Activation of factor IX by the reaction product of tissue factor and factor VII: additional pathway for initiating blood coagulation. Proc Natl Acad Sci U S A. 1977;74(12):5260-5264.

29. Banner DW, D'Arcy A, Chene C, et al. The crystal structure of the complex of blood coagulation factor VIIa with soluble tissue factor. Nature 1996;380(6569):41-46.

30. Rode-Mosbaek C, Nolan D, Persson E, Svergun DI, Bukrinsky JT, Vestergaard B. 

78. Bern M, Nilsen J, Ferrarese M, et al. An engineered human albumin enhances halflife and transmucosal delivery when fused to protein-based biologics. Sci Transl Med. 2020;12(565):eabb0580.

79. Marcos-Contreras OA, Smith SM, Bellinger DA, et al. Sustained correction of FVII deficiency in dogs using AAV-mediated expression of zymogen FVII. Blood. 2016;127(5): 565-571.

80. Miller GJ. Dietary fatty acids and the haemostatic system. Atherosclerosis. 2005; 179(2):213-227.

81. Moor E, Silveira A, van't Hooft F, et al. Coagulation factor VII mass and activity in young men with myocardial infarction at a young age. Role of plasma lipoproteins and factor VII genotype. Arterioscler Thromb Vasc Biol. 1995;15(5):655-664.

82. Kamikubo Y, Mendolicchio GL, Zampolli A, et al. Selective factor VIII activation by the tissue factor-factor VIIa-factor Xa complex Blood. 2017; 130(14):1661-1670

83. Nadir Y, Brenner B, Fux L, Shafat I, Attias J, Vlodavsky I. Heparanase enhances the generation of activated factor $\mathrm{X}$ in the presence of tissue factor and activated factor VII. Haematologica. 2010:95(11):1927-1934.

84. D'Alessandro E, Posma JJN, Spronk HMH, Ten Cate H. Tissue Factor (:Factor VIIa) in the heart and vasculature: more than an envelope. Thromb Res. 2018;168:130-137.

85. Rothmeier AS, Liu E, Chakrabarty S, et al. Identification of the integrin-binding site on coagulation factor VIIa required for proangiogenic PAR2 signaling. Blood. 2018:131(6):674-685.

86. Scarabin PY, Vissac AM, Kirzin JM, et al. Population correlates of coagulation factor VII. Importance of age, sex, and menopausal status as determinants of activated factor VII. Arterioscler Thromb Vasc Biol. 1996;16(9):1170-1176.

87. Green F, Kelleher C, Wilkes H, Temple A, Meade T, Humphries S. A common genetic polymorphism associated with lower coagulation factor VII levels in healthy individuals. Arterioscler Thromb. 1991;11(3):540546.

88. de Lange M, Snieder H, Ariens RA, Spector TD, Grant PJ. The genetics of haemostasis: a twin study. Lancet. 2001;357(9250):101105 .

89. Eriksson-Berg M, Deguchi H, Hawe E, et al. Influence of factor VII gene polymorphisms and environmental factors on plasma coagulation factor VII concentrations in middleaged women with and without manifest coronary heart disease. Thromb Haemost. 2005;93(2):351-358.

90. Mariani G, Bernardi F, Bertina R, et al. Serum phospholipids are the main environmental determinants of activated factor VII in the most common FVII genotype. European Union Concerted Action "Clotart". Haematologica. 1999;84(7):620626.

91. Sabater-Lleal M, Almasy L, MartínezMarchán E, et al. Genetic architecture of the F7 gene in a Spanish population: implication for mapping complex diseases and for functional assays. Clin Genet. 2006;69(5):420-428.

92. Smith NL, Chen MH, Dehghan A, et al Novel associations of multiple genetic loci with plasma levels of factor VII, factor VIII, and von Willebrand Factor: The CHARGE (Cohorts for Heart and Aging Research in Genome Epidemiology) Consortium. Circulation. 2010;121(12):1382-1392.

93. Tang W, Schwienbacher C, Lopez LM, et al. Genetic associations for activated partial thromboplastin time and prothrombin time, their gene expression profiles, and risk of coronary artery disease meta-analysis. Am J Hum Genet. 2012:91(1):152-162.

94. Taylor KC, Lange LA, Zabaneh D, et al. A gene-centric association scan for coagulation factor VII levels in european and African Americans: the candidate gene association resource (CARe) consortium. Hum Mol Genet. 2011:20(17):3525-3534

95. Kario K, Miyata T, Sakata T, Matsuo T, Kato H. Fluorogenic assay of activated factor VII. Plasma factor VIla levels in relation to arterial cardiovascular diseases in Japanese. Arterioscler Thromb. 1994;14(2): $265-274$

96. Olson NC, Raffield LM, Lange LA, et al. Associations of activated coagulation factor VII and factor VIIa-antithrombin levels with genome-wide polymorphisms and cardiovascular disease risk. J Thromb Haemost. 2018:16(1):19-30.

97. Martinelli N, Girelli D, Baroni M, et al. Activated factor VII-antithrombin complex predicts mortality in patients with stable coronary artery disease: a cohort study. J Thromb Haemost. 2016;14(4):655-666.

98. Baroni M, Martinelli N, Lunghi B, et al
Aptamer-modified FXa generation assays to investigate hypercoagulability in plasma from patients with ischemic heart disease. Thromb Res. 2020;189:140-146.

99. Merlini PA, Ardissino D, Oltrona L, Broccolino M, Coppola R, Mannucci PM Heightened thrombin formation but normal plasma levels of activated factor VII in patients with acute coronary syndromes. Arterioscler Thromb Vasc Biol. 1995;15(10): 1675-1679

100. Holm J, Tödt T, Berntorp E, Erhardt L. Failure of thrombolytic therapy in patients with myocardial infarction is associated with high plasma levels of factor VII antigen. Thromb Haemost. 1998;79(5):928931.

101.Folsom AR, Cushman M, Heckbert SR Ohira T, Rasmussen-Torvik L, Tsai MY Factor VII coagulant activity, factor VII $670 \mathrm{~A} / \mathrm{C}$ and $-402 \mathrm{G} / \mathrm{A}$ polymorphisms, and risk of venous thromboembolism. J Thromb Haemost. 2007;5(8):1674-1678.

102. Roldán V, Marín F, González-Conejero R, et al. Factor VII -323 decanucleotide D/I polymorphism in atrial fibrillation: implications for the prothrombotic state and stroke risk. Ann Med. 2008;40(7):553-559.

103. D'Ambrosio RL, D'Andrea G, Cappucci F, et al. Polymorphisms in factor II and factor VII genes modulate oral anticoagulation with warfarin. Haematologica. 2004;89 (12):1510-1516.

104.Buxhofer-Ausch V, Olcaydu D, Gisslinger $\mathrm{B}$, et al. Decanucleotide insertion polymorphism of F7 significantly influences the risk of thrombosis in patients with essential thrombocythemia. Eur J Haematol. 2014;93 (2):103-111

105. Ken-Dror G, Drenos F, Humphries SE, et al. Haplotype and genotype effects of the F7 gene on circulating factor VII, coagulation activation markers and incident coronary heart disease in UK men. J Thromb Haemost. 2010;8(11):2394-2403.

106. Donati MB, Zito F, Castelnuovo AD Iacoviello L. Genes, coagulation and cardiovascular risk. J Hum Hypertens. 2000;14(6) 369-372.

107.Bernardi F, Arcieri P, Bertina RM, et al Contribution of factor VII genotype to activated FVII levels. Differences in genotype frequencies between northern and southern European populations. Arterioscler Thromb Vasc Biol. 1997;17(11):2548-2553. 